\title{
Stability Analysis of Roadheaders
}

\author{
Omur Acaroglu Ergun \\ Istanbul Technical University, Mining Engineering Department \\ Maslak, Istanbul, Turkey \\ acaroglu@itu.edu.tr
}

\begin{abstract}
Nowadays, tunnel and underground mining drivage excavation methods have become fully mechanized. Roadheaders are one of the widely used mechanical excavation machines. They have exceptional place in this area because of their low cost and flexibilty. However they have some disadvantages such as not being used in hard and unstable formations. Improvements of this ability can cause stability problems. Therefore evaluation of stability states of these machines in different cutting conditions is vitally important. Stability analysis methods should be used for design and selection of roadheaders and when applying new technologies on them.
\end{abstract}

Keywords: Stability Analysis, Mechanical Excavation, Roadheaders

\section{Introduction}

Mechanical excavation methods have more advantages than the conventional drilling and blasting method. Roadheaders have an exceptional place among the other mechanized excavation systems, since they have lower initial investment costs than the full-face excavation machineries. They are also flexibly equipped to excavate galleries in various shapes [1]. However, they can not be used for hard cutting conditions and are more suitable for excavating stable rocks with low to medium hardness [2].

\section{Roadheaders and Stability Situations}

Roadheaders are generally classified as light, medium, heavy and extra heavy weight types. They can be used in higher strength rock as their weight increases, since the weight is proportional to cutting head power and boom forces. Machine weight is increased for more powerful machines to respond the high boom reaction forces. Otherwise machine stability is negatively affected and instability situations may occur [3-10].However the increase of weight causes a raise in the cost of it and also problems of the sinking of the machine in the wet grounds. Side and rear stabilizer pistons may not be useful if the tunnel has wide profile and wet grounds [6].

The stability of roadheaders is important for effective cutting process and some researchers express the importance of it and compare the longitudinal and the transverse head type roadheaders [3-8]. In transverse cutting heads are more sensitive for the stability of vertical directions, because of the main component of the resultant force acts vertically on the head. On the contrary, the longitudinal head type machines are more sensitive for the horizontal directions $[4,5,8]$. The longitudinal head machines are known as being unable to utilize the full weight of the machine and manufactured 20-25\% more weight than transverse type machine [6]. Therefore, It is reported that with the same cutting power the transverse type roadheaders can cut higher strength rock than the longitudinal type roadheaders considering to stability [4-6,8]. Since the longitudinal head type roadheader can cut vertically as well, the vertical stability should also be considered in the comparison of the stability of roadheaders [3,7]. All previous studies are based on practical observation or approximate evaluation about the stability of the roadheaders. The stability states of roadheaders must be sought in detail to produce more compact and more capable of cutting conditions for high strength rocks. 
There are also some researches carried out to increase the roadheaders cutting efficiency without increasing the dimension of roadheaders. These studies are mainly focused on auxiliary cutting assistances, new design cutting heads, new type of cutting tools, water jets on cutting heads and control system addition to roadheaders [11-17].

One of the new technology to improving the efficiency of cutting ability of roadheader is mini-disc cutters. Disc cutters are becoming a standard cutting tool in hard rock formation. However standard disc cutters were too big for mounting on cutting head that is less than 2 meters diameter and their thrust levels are much higher than roadheaders can handle it. Due to these mini-disc cutting tools were designed and these tools and considered as an alternative cutting tools for roadheaders $[18,19]$.

\section{A Method for Stability Analysis of Roadheaders and Usage of It}

\subsection{Stability Analysis Method for Roadheaders}

A method was developed to analyze the stability of roadheaders quantitatively and a computer program was written [20,21]. It has been conducted for turning around vertical axis of the machine, turning to the side and back direction of the machine and sliding stability states in "sumping, arcing, lifting and lowering" cutting modes of transverse or longitudinal head type of roadheader. For each situation, stability state equations have been established and then a computer program based on these equations has been developed to make stability analyses along the whole tunnel face or for a particular point on the face. The stability state equations have been based on the calculation of three moment values of $\mathrm{x}, \mathrm{y}, \mathrm{z}$ directions and the sliding state of a roadheader as given in Fig. 1. The method is explained below:

- Calculate the moment values with respect to $\mathrm{C}$ point on the vertical $\mathrm{y}$-axis taken in the plane of the center of gravity that allows us to control if the roadheader turns around vertical axis.

- Calculate the moment values with respect to B point on the z-axis taken in the plane of machine floor that allows us to control if the roadheader turns to both side directions.

- Calculate the moment values with respect to A point on the $\mathrm{x}$-axis taken in the plane of machine floor that allows us to control if the roadheader turns to back or not.

- Estimate the sliding state of the roadheader along the z-axis in the plane of the floor $[20,21]$.
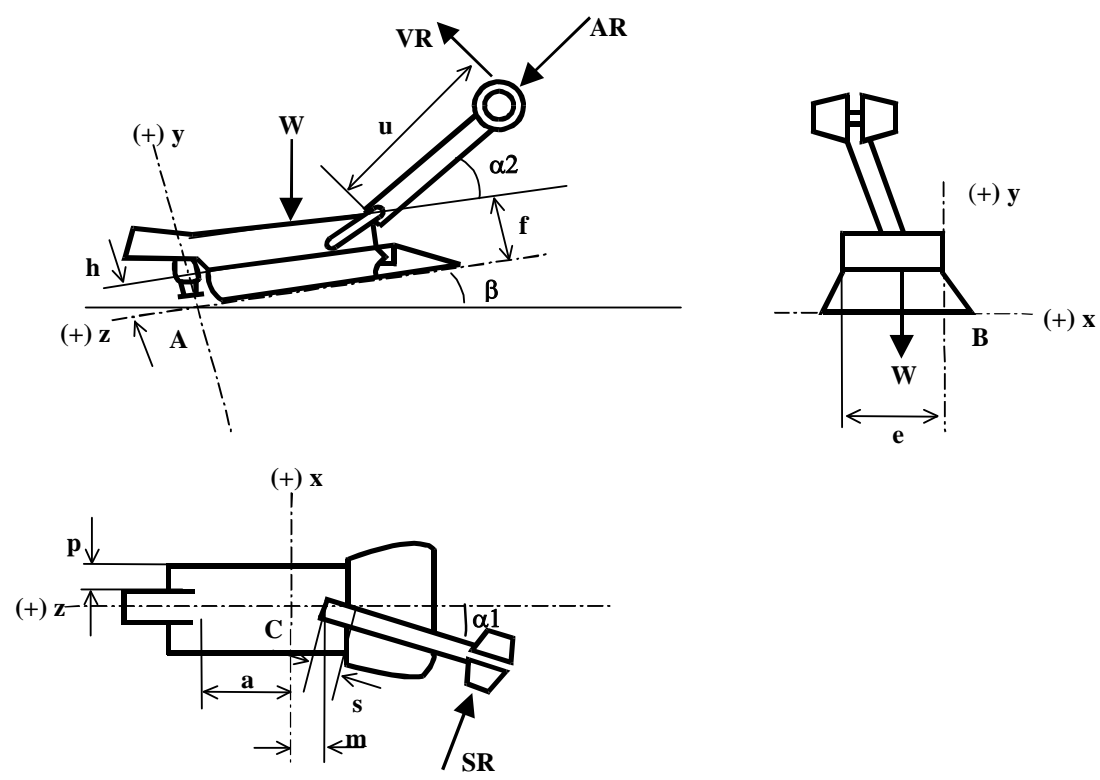

Fig. 1: Machine design parameters and boom reaction forces of a transverse type roadheader.

As seen from the Fig. 1, The parameters used, which affect the machine stability, are; W, machine weight; e, machine width; $\mathrm{p}$, the width of each track; $\mathrm{u}$, the length of the boom; $\mathrm{m}$, the distance between the start of the boom and the center of gravity; a, the distance between the back leg of the machine and the center of gravity; f, the distance between the ground and the boom when it is parallel to the ground; s, the distance between the horizontal rotation point and the vertical rotation point of the boom; a1, maximum horizontal position angle of the boom; a2, maximum upward 
vertical position angle of the boom; a3, maximum downward vertical position angle of the boom; 1 , friction coefficient between floor and the machine tracks; $b$, gradient of the tunnel.

The forces in the cutting process are used in the stability analysis of the roadheaders which are machine weight and boom reaction forces. Boom reaction forces have three components of the resultant forces acting on the cutting head "an axial force (AR), slewing force (SR) and vertical force (VR)" that AR acts parallel to the boom axis, SR acts along the cutting way and perpendicular to AR. VR is on the same plane of SR and acts perpendicular to it (Fig. 1)

Using machine design parameters and defined reaction forces, three moment equations and an equation of sliding state have been established for transverse and longitudinal cutting head type roadheaders for all cutting modes. As chancing the cutting modes, roadheader stability is affected due to changes in the directions of the boom reaction forces $[20,21]$.

Based on the method, a computer program shown in Fig. 2 has been written by using $\mathrm{C}++$ programing language. The values of the established moment equations that is referred as stability state of a roadheader can be obtained from these computer program. This computer program can calculate stability values either at a particular point of the tunnel face or along the whole face. Using moment/force values and tunnel profile data, isomoment graphics of the stability states can be drawn. Thus, the stability states can be observed along the tunnel profile such as Fig. 3 which shows stability state values of turning around the vertical axis of a transverse type roadheader. 


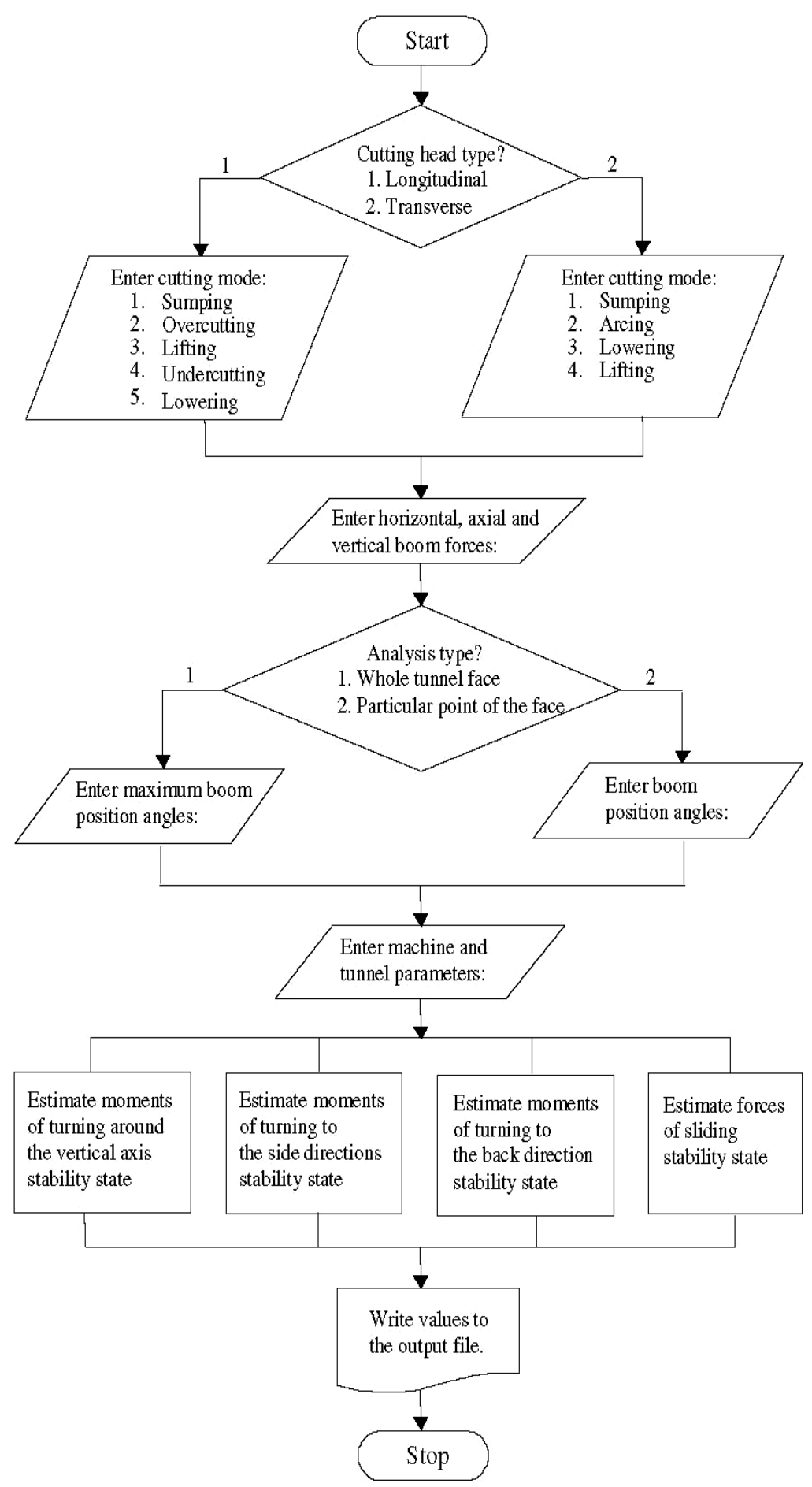

Fig. 2: Flowchart of computer program of stability analysis. 


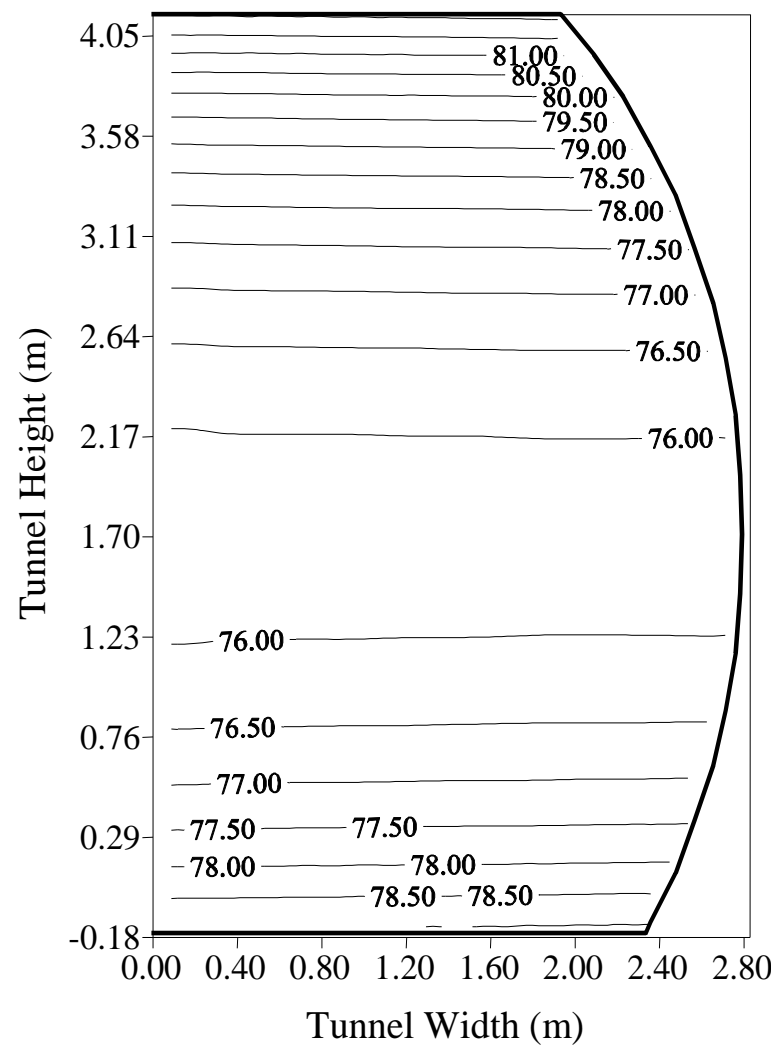

Fig. 3: Stability state values of turning around the vertical axis of a transverse type roadheader.

\subsection{Usage of Stability Analysis Method for Roadheaders}

Roadheaders can be analysed for given in rock cutting condition by using this method and any possible stability problems are determined before occurred. Furthermore quantitative stability state values can be used as selection criteria with other quantitative criteria such as cutting rate, power of the machine, max. applicable boom forces etc [22, 23]. Roadheaders can be compared with selection criteria including stability values by applying decision methods [22, 23].

As an example usage of this program, the effects of machine design parameters on machine stability were determined in a roadheader that is in operation in a Turkish Coal Mine. It has been concluded that the machine weight has a great influence on the stability as defined in the previous studies. The increased values of the machine width, the width of tracks, the distance between the back leg of the machine and the center of gravity have contributed positively to some of the stability states of the machine or vice versa. However, the stability of the specified roadheader was negatively affected by the increased values of the boom length and the other remaining machine design parameters [24]. The method developed may be useful for the roadheader manufacturers and the machine users as the effects of the machine design parameters on machine stability and machine integrity can be determined for different tunnel conditions.

Using this program, the effects of spherical, conical and combined heads on a specified longitudinal roadheader were also determined [25]. From the results, the most critical stability state of the roadheader was turning around the vertical axis. The stability of the roadheader was positively affected by an increase in the tilt angles of the picks for all cutting head shapes. The moment values of the spherical heads were found to be lower than those of the conical heads for the most critical stability state - turning around the vertical axis of the machine. The cutting head shapes also have effects on the other stability states, as the sliding state of the roadheader was affected by the cutting head shape. The increase in the tilt angles of the picks affected negatively the sliding state of the machine for all head shapes, especially conical heads having high tilt angles of the picks [25].

The method has also used to analyse a roadheader with mini disc. According to results of this analysis, the minidiscs equipped roadheader has serious stability problems. The reason of the stability problems is bigger reaction forces 
of mini disc cutters which apply to the boom than forces of point attack cutters'. According to stability analysis for roadheader with point attack cutters and with mini-disc there might be a stability problem not only in arcing cutting mode but also in lowering and sumping cutting modes [26].

\section{Conclusion}

These results show that success of a roadheader performance and design should also include the stability analysis of the machine. Unstable states can cause energy consumption without production thus this will increase the specific energy and reduce the cutting performance of the machine. Also instability of machines can cause accidents and damage to operators and the machines.

A method has been developed and a computer program has been written to make stability analysis of roadheaders. This method leads to determine moment/force values of the machine stability states such as turning around the vertical axis, turning to the side directions, turning to the back direction and sliding for all cutting modes. When they get bigger values than zero the roadheader has higher stability conditions.

Stability analysis of roadheaders must be considered for evaluating roadheader efficiency. The stability analysis should be used as one of machine selection criteria since the stability has effects on cutting performance. It is also important to evaluate the stability of roadheaders in designing of the machine and cutting heads. Even new technological applications on roadheaders, stability states of them must be considered.

\section{References}

[1] M. E. Breitrick, "Using a roadheader for underground gold mining," Mining Engineering, pp. 43-46, 1998.

[2] C. D. Breeds and J. J. Convay, "Rapid excavation," Mining Engineering Handbook, vol. 2, H. L. Hartmand, Ed. Colorado: Society for Mining, Metallurgy and Exploration Inc., pp. 1971-1907, 1992.

[3] P. Frenyo and W. Lange, "Design of cutting heads for optimal cutting performance," Gluckauf Mining Reporter, pp. 4-7, 1994.

[4] K. H. Gehring, "A cutting comparison," Tunnels and Tunnelling, vol. 21, 1989, pp. 27-30.

[5] H. W. Kleinert, "New test-bed results for cutting headings on selective-cut heading machines," Gluckauf, vol. 118, pp. 459-464, 1982.

[6] W. J. Kogelman, "1ncreased productivity through boom-type continous miners," South African Mining World, August, pp. 63-80, 1982.

[7] J. McDermott, "Roadheaders characteristics and capabilities," in 6th Coal Congress of Turkey, Zonguldak, vol. 2, pp. 119-139, 1988.

[8] W. Menzel and P. Frenyo, "Selective-cut roadheading machines with longitudinal and transverse cutting heads," Gluckauf, vol. 117, no. 5, pp. 284-287, 1981.

[9] O. Z. Hekimoglu, "Studies in the excavation of selected rock materials with mechanical tools," Ph.D. dissertation, University of Newcastle Upon Tyne, 1984.

[10] O. Z. Hekimoglu, "The effects of the cutting heads on performance of the roadheaders," in Coal Congress of Turkey 6th, Zonguldak, pp. 111-140, 1986.

[11] R. Aisawa, K. Sakai, K. Itoh and K. Tsuji, "Development of boom type tunnelling mackine for hard rock," in 6 th Australian Tunnelling Conference, Parkville: AusIMM Melbourne, pp. 209-213, 1987.

[12] E. P. Deliac, "Recent developments in the design and optimisation of drum type cutting machines in France," in 1985 Rapid Excavation and Tunnelling Conference, vol. 1, New York: AIME New York, pp. 264-283, 1985.

[13] S. Liu, Z., Liu, X., Cui, H., Jiang, "Rock breaking of conical cutter with assistance of front and rear water jet," Tunn. Undergr. Sp. Technol., vol. 42, pp. 78-86. doi:10.1016/j.tust.2014.02.002, 2014

[14] X. Lu, D. Wang, C. Xu, C. Zhu, W. Shen, "Experimental investigation and field application of foam used for suppressing roadheader cutting hard rock in underground tunnelling," Tunn. Undergr. Sp. Technol., vol. 49, pp. 1-8. doi:10.1016/j.tust.2015.03.011, 2015.

[15] M. Roman, B. Josif, D. Nikolay, "Development of position system of a roadheader on a base of active IRsensor," Procedia Eng., vol. 100, pp. 617-621. doi:10.1016/j.proeng.2015.01.412, 2015.

[16] S. T. A., Gillani, N., Butt, "Excavation technology for hard rock - problems and prospects." Pak. J. Engg. \& Appl. Sci., vol, 4, no. 1, pp. 24-33, 2009.

[17] P. Gospodarczyk, K. Kotwica, G. Stopka, “A New Generation Mining Head With Disc Tool of Complex Trajectory / Głowica Urabiająca Nowej Generacji Z Narzędziami Dyskowymi O Złożonej Trajektorii,” Arch. Min. Sci., vol. 58, pp. 985-1006. doi:10.2478/amsc-2013-0069, 2013. 
[18] J. Rostami, B. Asbury, L. Gertsch, L. Ozdemir, "Laboratory testing and performance evaluation of a mini-disc equipped roadheader cutterhead for Yucca Mountain welded tuff," Las Vegas: Department of Energy Yucca Mountain Project Office, 1995.

[19] J. Rostami, D. M. Neil, L. Ozdemir, "Roadheader Application for The Yucca Mountain Experimental Study Facility," Las Vegas: Colorado School of Mines, Earth Mechanic Institute, 1993.

[20] O. Acaroglu, "Stability analysis of the boom type tunnelling machines and optimum selection," Ph.D. dissertation, Istanbul Technical University, Turkey, 2004.

[21] O. Acaroglu and H. Ergin, "A new method to evaluate roadheader operational stability," Tunneling and Underground Space Technology 21, pp. 172-179, 2006.

[22] O. Acaroglu, C. Ferigunoglu and D. Tumac, "Selection of roadheaders by fuzzy multiple attribute decision making method," IMM Mining Technology, vol. 115, no. 3, pp. 1-8, 2006.

[23] O. Acaroglu, H. Ergin and S. Eskikaya, "Analytical hierarchy process for selection of roadheaders," The Journal of the South African Institute of Mining and Metallurgy, vol. 106, pp. 569-575.

[24] H. Ergin and O. Acaroglu, "The effect of machine design parameters on the stability of a roadheader," Tunnelling and Underground Space Technology Incorporating Trenchless Technology Research, vol. 22, pp. 8089, DOI:10.1016/j.tust.2006.04.003, 2007.

[25] O. Acaroglu and H. Ergin, "The effect of cutting head shapes on roadheader stability," Mining Technology, vol. 144, no. 3, pp. A140-A146, 2005.

[26] O. Acaroglu and C. Erdogan, "An Assessment of Stability Analysis of Roadheaders with Mini-disc," 6th International Conference on Computer Applications in the Minerals Industries, Istanbul, Turkey, pp. 5-7, 2016. 